\title{
Absence of genetic linkage of chromosome 5 q31 with asthma and atopy in the general population
}

Atsushi Kamitani, Zilla Y H Wong, Phillip Dickson, Lynne van Herwerden, Joan Raven, Andrew B Forbes, Michael J Abramson, E Haydn Walters, Stephen B Harrap

Department of

Physiology

A Kamitani

Z Y H Wong

S B Harrap

Department of Biochemistry and

Molecular Biology

P Dickson

University of Melbourne, Parkville,

Victoria 3052,

Australia

Department of Epidemiology and

Preventive Medicine,

Monash Medical

School, Prahan,

Victoria 3181,

Australia

$\mathrm{L}$ van Herwerden

A B Forbes

M J Abramson

Department of

Respiratory Medicine,

Alfred Hospital and

Department of

Medicine, Monash

Medical School,

Prahan, Victoria 3181,

Australia

J Raven

E H Walters

Correspondence to: Professor S B Harrap.

Received 7 February 1997 Returned to authors

10 April 1997

Revised version received

9 May 1997

Accepted for publication

13 May 1997

\begin{abstract}
Background - Clinical asthma is associated with increased serum total immunoglobulin E (IgE), atopy (skin prick test positivity to common aeroallergens), and bronchial hyperreactivity (BHR) to non-specific stimuli (positive methacholine challenge test). A region on chromosome 5q31-33 has been linked with increased total serum IgE and BHR. A study of the genetic linkage of this region with clinical asthma and atopy was therefore undertaken.
\end{abstract}

Methods - A polymorphic microsatellite marker in chromosome 5q31 (D5S399) was studied in 119 sibling pairs recruited from the general population who shared asthma, atopy, and/or BHR. Based on our population distribution of 13 different alleles, it was expected that by chance alone sibling pairs would share on average 1.24 alleles and that a significant excess would indicate genetic linkage.

Results - No evidence of linkage was found in 45 siblings concordant for asthma (shared alleles $=1.09, p=0.95$ ), in 103 sibling pairs with atopy (shared alleles $=1.18$, $p=0.82$ ), in 51 sibling pairs with BHR (shared alleles $=1.22, p=0.62$ ), or in 68 sibling pairs who shared atopy in the absence of BHR (shared alleles $=1.22, p=$ 0.61). A slight non-significant excess of shared alleles $(1.44, p=0.11)$ was observed in siblings who shared BHR without atopy. Conclusions - No evidence of genetic linkage of chromosome 5 q31 with either clinical asthma or atopy was therefore detected in the population studied. Linkage between chromosome $5 q$ and BHR needs further investigation.

(Thorax 1997;52:816-817)

Keywords: asthma, genetics, linkage.

The genetics of asthma has been inferred from linkage studies of atopy, bronchial hyperreactivity (BHR), and total serum IgE levels. These phenotypes show a high degree of heritability ${ }^{1}$ but do not always coincide. ${ }^{23}$ Independence, overlap, and interaction between different phenotypes confounds attempts to define specific genetic predisposition.

We have recently shown that the high affinity immunoglobulin $\mathrm{E}$ ( $\operatorname{IgE}$ ) receptor gene on chromosome $11 \mathrm{q} 13$ is linked with clinical asthma. ${ }^{4}$ In our population this linkage was explained by BHR, but not atopy. ${ }^{4}$ Chromosome 5q31-33 may be relevant to asthma as genetic variation in this region appears to influence total serum IgE levels and a number of candidate genes reside in this chromosomal vicinity. ${ }^{5-7}$ Total serum IgE levels correlate with clinical asthma and allergy ${ }^{3}$ but linkage studies of chromosome $5 \mathrm{q}$ with clinical asthma or atopy have not been reported. ${ }^{8}$

Methods

We used a polymorphic microsatellite marker studied previously ${ }^{5}$ on chromosome $5 \mathrm{q} 31$ (D5S399) to examine linkage in sibling pairs recruited from the general population who shared asthma, atopy, and/or BHR. The selection of subjects and phenotypic determination were as described previously. ${ }^{4}$ In brief, recruitment for screening was part of the European Community Respiratory Health Survey which has been described elsewhere. ${ }^{9}$ We screened 4500 randomly selected young adults (aged 20-44 years) and a subgroup of 757 attended our respiratory function laboratory for detailed phenotype characterisation. Clinical asthma was defined using a validated questionnaire, ${ }^{9}$ as wheeze or the use of asthma medications in the previous 12 months. Skin sensitivity (a weal of greater than $3 \mathrm{~mm}$ diameter) to common aeroallergens was used to define atopic status. ${ }^{4}$ A methacholine challenge was used for bronchial provocation to determine BHR which was defined as a reduction in forced expiratory volume in one second $\left(\mathrm{FEV}_{1}\right)$ of $20 \%$ or more at a cumulative dose of less than or equal to $2 \mathrm{mg}(10.2 \mu \mathrm{mol})$ of methacholine. ${ }^{4}$ We selected individuals with asthma, atopy, or BHR and, by testing their siblings, we identified 119 affected sibling pairs who shared at least one of the phenotypes.

Genomic DNA was extracted from $10 \mathrm{ml}$ samples of blood in EDTA by standard techniques. ${ }^{4}$ The D5S399 PCR primers and amplification conditions were as described previously. ${ }^{5}$ Allele sizes and genotypes were determined independently by two investigators (AK, ZYHW) who were unaware of the phenotype data. Linkage analysis was performed using the sibling pair method ${ }^{10}$ based on the number of alleles shared by affected siblings in relation to that expected by chance alone. Linkage between the marker and phenotype was inferred when the number of alleles shared 
Table 1 Allele sharing in groups of affected siblings

\begin{tabular}{lccccc}
\hline Concordance for & \multirow{2}{*}{$\begin{array}{l}\text { No. of sibling } \\
\text { pairs }\end{array}$} & \multicolumn{2}{l}{ No. of shared alleles } & \\
\cline { 3 - 5 } & & Observed & Expected & \% excess & p value* \\
\hline Asthma & 45 & 49 & 55.9 & -12.3 & 0.95 \\
Atopy & 103 & 122 & 127.9 & -4.6 & 0.82 \\
BHR & 51 & 62 & 63.3 & -2.1 & 0.62 \\
Atopy alone & 68 & 83 & 84.5 & -1.7 & 0.61 \\
BHR alone & 16 & 23 & 19.9 & 15.7 & 0.11 \\
Atopy with BHR & 35 & 39 & 43.5 & -10.3 & 0.88 \\
\hline
\end{tabular}

$\mathrm{BHR}=$ bronchial hyperreactivity.

* Based on one sided test.

by affected siblings exceeded significantly that expected by chance. To clarify linkage of this marker with atopy or BHR alone, we also analysed sibling pairs who were concordant for atopy without BHR or concordant for BHR without atopy.

These studies were approved by the Alfred Hospital ethics review committee.

\section{Results}

We found 13 different D5S399 alleles in our population with a calculated heterozygosity of $81 \%$. The sizes of alleles were assessed by specific molecular markers and DNA sequencing reactions run on each gel. The most common alleles were 115,117 , and 127 base pairs in length. Based on the observed distribution we expected that sibling pairs chosen at random would share, on average, 1.24 alleles. In 45 sibling pairs who shared clinical asthma we observed an average of 1.09 shared alleles $(\mathrm{p}=$ 0.95). In 103 sibling pairs characterised with atopy (table 1 ) we observed 122 shared alleles (1.18 shared alleles per pair, $p=0.82$ ). Of these, 68 siblings were concordant for atopy without BHR and they shared 83 alleles (1.22 shared alleles per pair, $p=0.61)$. Concordance for BHR was found in 51 siblings in whom a total of 62 shared alleles were observed (1.22 shared alleles per pair, $\mathrm{p}=0.62$ ). In 16 sibling pairs concordant for BHR but not atopy we observed a slight excess of shared alleles (1.44 shared alleles per pair, $p=0.11)$. However, this excess was not statistically significant (table 1). Sibling pairs concordant for both atopy and BHR shared only 1.11 alleles on average $(\mathrm{p}=0.88)$.

\section{Discussion}

This is the first report of a linkage study between asthma and atopy and chromosome 5q31. Previous studies have reported linkage of this locus with total serum IgE levels ${ }^{56}$ and linkage with $\mathrm{BHR}^{7}$ which has been disputed. ${ }^{8}$ The association between serum IgE levels and asthma and allergy ${ }^{3}$ led previous investigators to suggest that loci on chromosome $5 \mathrm{q} 31$ might also predispose to asthma. However, we were unable to demonstrate linkage between chromosome $5 \mathrm{q} 31$ and clinical asthma or atopy.

This negative result may reflect insufficient statistical power. Precise calculations of statistical power are not possible as they depend on specification of unknown parameters such as the contribution of the suspected locus to the disease, the genetic heterogeneity of the disease (number of implicated loci, respective effect of each locus, loci interactions), and the rates of recombination between the marker and the susceptibility locus. However, it is possible to estimate, for any given sample size, the percentage of excess allele sharing required to declare statistical significance at the (one sided) $5 \%$ level. For 16 sibling pairs an excess sharing $21.2 \%$ would be declared as statistically significant, whereas for 50 and 100 sibling pairs the excesses required are $12.1 \%$ and $8.6 \%$, respectively. Other than siblings concordant for BHR alone, none of the sibling pair groups showed any excess of allele sharing.

The absence of linkage between chromosome $5 \mathrm{q} 31$ and atopy is not entirely unexpected as atopy may be more closely related to specific IgE antibodies than to total serum IgE levels. ${ }^{11}$ Even where linkage of chromosome $5 \mathrm{q} 31$ with total $\operatorname{IgE}$ has been found, no linkage with $\operatorname{IgE}$ specific to common aeroallergens could be demonstrated. ${ }^{5}$

In an analysis of a subset of a Dutch study, chromosome 5q31-33 was linked with BHR. The strongest linkage was seen for markers slightly more towards the end of the chromosome than D5S399. We found no evidence of linkage between D5S399 and BHR in 51 affected sibling pairs, but there was a $16 \%$ excess of shared alleles in 16 sibling pairs who shared BHR in the absence of atopy. Although not of statistical significance, this observation may be important as more distal markers might reveal stronger linkage to BHR. Detailed mapping of chromosome $5 q$ is needed to examine the possibility that a gene affecting BHR is in the vicinity.

In conclusion, our findings indicate that in an Australian population chromosome $5 \mathrm{q} 31$ does not exert a substantial influence on the inheritance of asthma or on atopy. Linkage between chromosome $5 \mathrm{q} 31$ and BHR warrants further study. The work was supported by the Monash University De-
velopment Fund, Alfred Hospital Medical Research Advisory velopment Fund, Alfred Hospital Medical Research Advitee and Allen and Hanburys (Glaxo Australia).

1 Hopp RJ, Bewtra AK, Watt GD, Nair NM, Townley RG. Genetic analysis of allergic disease in twins. F Allergy Clin Immunol 1984;73:265-70.

2 Sibbald B, Horn MEC, Brain EA, Gregg I. Genetic factors in childhood asthma. Thorax 1980;35:671-4.

3 Burrows B, Martinez FD, Halonen M, Barbee RA, Cline MG. Association of asthma with serum IgE level and skinMG. Association of asthma with serum IgE level and skin-

4 Van Herwerden L, Harrap SB, Wong ZYH, Abramson MJ Kutin JJ, Forbes AB, et al. Linkage of high-affinity IgE Kutin JJ, Forbes AB, et al. Linkage of high-affinity IgE receptor gene with bronchial hyperreactivity

sence of atopy. Lancet 1995;346:1262-5.
5 Marsh DG, Neely JD, Breazeale DR, Ghosh B, Friedhoff LR, Erlich-Kautzky E, et al. Linkage analysis of IL4 and other chromosome 5q31.1 markers and total serum immunoglobulin E concentrations. Science 1994;264 $1152-6$.

6 Meyers DA, Postma DS, Panhuysen CIM, Xu J, Amelung PJ, Levitt RC, et al. Evidence for a locus regulating total serum IgE levels mapping to chromosome 5. Genomics 1994;23:464-70.

7 Postma DS, Bleecker ER, Amelung PJ, Holroyd KJ, Xu J, Panhuysen CIM, et al. Genetic susceptibility to asthma: bronchial hyperresponsiveness coinherited with a major gene for atopy. $N$ Engl f Med 1995;333:894-900.

8 Daniels SE, Bhattacharrya S, James A, Leaves NI, Young A, Hill MR, et al. A genome-wide search for quantitative trait loci underlying asthma. Nature 1996;383:247-50.

9 Burney PGJ, Leuzynska C, Chinn S, Jarvis D. The European Community Respiratory Health Survey. Eur Respir f 1994; 7:954-60.

10 Lange K. A test statistic for the affected sib pair method. Ann Hum Genet 1986;50:283-90.

11 Panzani RC, Mercer P, Delord Y, Riva G, Falagiani P, Reviron D, et al. Prevalence of patent and latent atopy among a general normal adult population in the south east of France by RAST investigation and correlation with circulating total IgE levels. Allergol Immunopathol 1993; 21:211-9. 